\title{
Síndrome neurocutáneo: neurofibromatosis tipo 1
}

\section{The neurocutaneous syndrome: neurofibromatosis type 1}

\author{
Rachid Bouchentouf I
}

Bouchentouf R. Síndr ome neurocutáneo: neurofibromatosis tipo I. Rev Soc Peru Med Interna. 2020;33(3): I 25.

https://doi.org/10.36393/spmi.v33i3.552

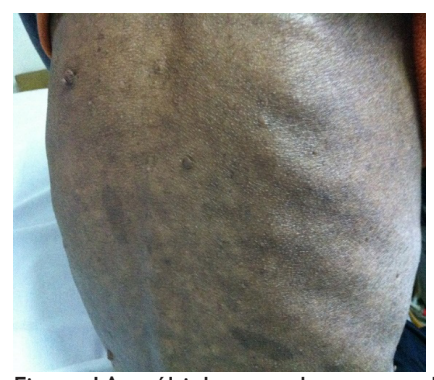

Figura IA: múltiples manchas cutáneas café con leche

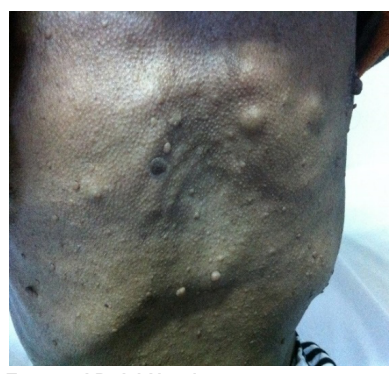

Figura IB: Múltiples neurofibromas cutáneos
Varón de 55 años de edad, gran fumador, antecedente de TB pulmonar en 1985. En sus antecedentes familiares, padre y una hermana presentaban manchas cutáneas "café con leche". Acudió al servicio por disnea y dolor torácico de dos semanas de evolución, sin fiebre. En el examen físico, se encontró numerosas maculas "café con leche" y neurofibromas cutáneos dispersos en todo el cuerpo. (Figuras 1A y 1B)

La radiografía torácica mostró hiperinflación del pulmón izquierdo y secuelas de TB pulmonar en el pulmón derecho. La RMN evidenció una lesión quística rodeada de pared fina a nivel de la región prevertebral izquierda T11-T12, con señal de LCR en secuencia T 1 y T2, compatible con un meningocele (Figura 2).

La neurofibromatosis (NF) de von Recklinghausen tipo 1 es la facomatosis más frecuente, con una incidencia de 1 por cada 3000 nacimientos a nivel mundial. ${ }^{1}$ Es una enfermedad multisistémica con afectación predominante de piel y sistema nervioso. Las lesiones dérmicas más comunes son maculas "café con leché" y efélides en áreas no fotoexpuestas. Entre un 5-10\% de los pacientes con NF tipo 1 presentan un tumor neurogénico endotorácico. ${ }^{2}$ los meningoceles son lesiones raras y pueden ser aislados o presentes en NF tipo 1 en $85 \%$ de casos. La RMN sigue siendo el estudio de elección para el diagnóstico de

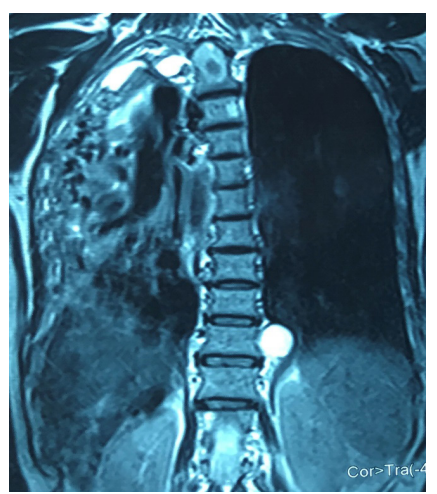

Figura 2: RMN en corte coronal: una masa quística en la región prevertebral izquierda al nivel TII-TI2.

meningocele, donde se describe como una lesión quística con señal de LCR rodeada de una fina pared perceptible. El meningocele debe distinguirse del tumor mediastínico posterior, como el neurofibroma, el neuroblastoma y el ganglioneuroma. ${ }^{3}$ El tratamiento quirúrgico depende del tamaño y la complicación del meningocele, y es indicado en caso de dolor, déficit neurológico o cuando el meningocele crece. En este caso, se decidió la abstención quirúrgica debido por el tamaño y la ausencia de trastornos neurólogicos ; y, solo seguimiento clínico y radiológico

\section{REFERENCIAS BIBLIOGRÁFICAS}

1. Boyd KP, Korf BR, Theos A. Neurofibromatosis type 1. J Am Acad Dermatol. 2009;61(1):1-14.

2. Meningocele intratorácico en la enfermedad de Von Recklinghausen: presentación de un caso. Archivos de Bronco neumología. 1995, 31(8): 60-62.

3. Wang MY, Levi AD, Green BA. Intradural spinal arachnoid cysts in adults. Surg Neurol. 2003, 60:49-55.

\section{CORRESPONDENCIA:}

Rachid Bouchentouf

bouchentouf_rachid@yahoo.fr

Fecha de recepción: 24-06-2020.

Fecha de aceptación: 03-08-2020 